

\title{
CRYOGENIC COOLING OF X-RAY CRYSTALS USING A POROUS MATRIX
}

\author{
Tuncer M. Kuzay \\ Advance Photon Source \\ Argonne National Laboratory \\ Argonne, Illinois 60439 \\ U.S.A
}

It is well established that $\mathrm{Si}$ and $\mathrm{SiC}$ have very desirable thermophysical properties (principally thermal conductivity and the thermal expansion) at cryogenic temperatures. This feature makes cryo-cooled optics potentially a good candidate for the first optical crystal of the presently built third generation synchrotron machines with very high heat flux levels. Currently, there is a great deal of interest in such cryo-cooled crystals pursued both experimentally and analytically. The analytical studies involve cut micro or capillary channel crystals. As opposed to the machined channels sorous matrices provide significant advantages $(1)$. They operate very quietely. Such matrices are known to affect superior heat transfer enhancement. Data available in open literature suggest that surface heat flux levels up to $\sim 8 \mathrm{~kW} / \mathrm{cm}^{2}$ are possible. For cryogens for which the boiling heat transfer heat flux is rather a low value in conventional geometries, the enhancement available with such matrices is a very significant characteristic. Cryogens are poor thermal conducters themselves. The fact that at the cryogenic temperatures the $\mathrm{Si}$ and/or $\mathrm{SiC}$ matrix itself becomes highly conductive, the matrix distributes the surface heat flux into the full volume effectively offsetting the poor conductivity of the coolant. In addition the tortuous path of the coolant through the matrix increases the dwell time for better heat transfer, however, at the expense of increased pressure drop.

In this study, thermal conductivity of such composite matrices and the effective heat transfer coefficient obtainable using them are investigated. A first optics crystal model of Si with $\mathrm{Si}$ and/or Sic porous matrix as its heat exchanger and subject to prototypic synchrotron level heat flux is analyzed and limits of the cooling possible with liquid nitrogen in single phase and subcooled boiling heat transfer modes are delineated. (2)

(1) T M. Kuzay, " Process of Making Cryogenically Cooled High Thermal Performance Crystal Optics", U.S Patent Applied for,\#\$69384 July 1990

(2) This work is supported by the U.S. Department of Energy, BES-Materials Sciences, under Contract W-31-109-Eng-38 


\section{INTRODUCTION}

The status of the Advanced Photon Source (APS) project at Argonne National Laboratory (ANL) has been described in [1]. A detailed description of the charecteristics of the APS machine has been provided in [2]. Due to the high energies involved with these new generation synchrotron machines, ard ever increasing demand for higher brilliance, the first optics on the beam line continues to be the prize piece for the current R\&D. In the case of the APS Table 1 [ 3 ] shows clearly the very high heat flux levels associated with Undulator A and B (580and $430 \mathrm{~W} / \mathrm{mm}^{2}$ respectively at $24 \mathrm{~m}$ and on normal incidence) of the current designs. A recent workshop at ANL [4] focused principally on the first optics of a two crystal monochromator which was attended by well over 100 visitors world over. This alone shows the interest and the keen competitive spirit that exists among the world researchers associated with the new generation machines $(6-8 \mathrm{GeV})$ to solve the horrendous optics problem of the first crystal.

As this conference amply proves the current research and development (R\&D) in synchrotron facilities on the cooling of the high heat load optics seem to be proceeding along use of liquid metals and crygonics with macro channels; use of water with micro channels ; and, use of innovative crystal geometries (inclined and assymetric crystal geometries) to broaden the beam footprint In this paper, we will focus on a novel method of using higly conductive porous matrices (foams) in conjuction with cryogenic cooling in single phase [5]. The choice for the crygenic cooling has been mentioned in literature[6]. Basically, the pure silicon crystal manifests an interesting thermal expansion characteristic at cryogenic temperatures. The thermal expansion of the crystal is zero at $.110 \mathrm{~K}$ as well as at a lower temperature of $\sim 30 \mathrm{~K}$. . The former temperature is maintainable economically using a cheap cryogen such as LN2. The zero linear expansion coefficient is interesting for the silicon crystals on the APS beam line as this will help minimize the structural distortions in the crystal under thermal loading. Even above and below this mark, the thermal expansion coefficient is still very small. Therefore, if the crystal temperature cannot be maintained uniformly at $110 \mathrm{~K}$, the resulting structural distortions will still be small at such temperatures. 
Another advantage of the low temperatures in the crystal is such that it thermal conductivity improves very significantly compared to room temperatures (-ig. 2). For example, at $100 \mathrm{~K}, \mathrm{k}=8.8 \mathrm{~W} \mathrm{~cm}^{-1} \mathrm{~K}^{-1}$, whereas at $300 \mathrm{~K}, \mathrm{k}=1.5 \mathrm{~W} \mathrm{~cm}^{-1} \mathrm{~K}^{-1}$, an improvement almost six folds. This means that the surface or near surface volumetric heating of the crystal under APS radiation will be conducted away rapidly and uniformly and transported to the cryogenic coolant even with relatively thick crystals.

For operational stability and safety it is very desirable that the coolant remains single-phase or in the sub-cooled convective boiling mode.

As for the use of porous matrices, it is evident that the porous matrix offers some unique features. These matrices are readily available in industry today for many desirable crystal/mirror materials including $\mathrm{SiC}, \mathrm{Be}$ and $\mathrm{BeO}$ and others. In this paper we will focus on $\mathrm{SiC}$ because of its cheap and ready availability, and its close thermo-mechanical compatibility with single Si crystal. Behaviour of $\mathrm{SiC}$, for example, at $\mathrm{LN} 2$ temperatures is very much like that of $\mathrm{Si}$.

Porous matrices can be made with various porosities. At high porosities, the porous matrix behaves like a macro channel crystal. At low porosities it behaves like a micro channel crystal. With no need for elaborate machining, porous matrices bonded to a single crystal $\mathrm{Si}$ faceplate in various forms as shown in Fig.1 provide macro or micro channel, cryogenically coolable crystal. In short, a porous matrix is nature's equivalent to man made macro or micro channels. Such a conceptual crystal structure is depicted in Fig.2.

Porous matrices made of $\mathrm{Si}, \mathrm{SiC}, \mathrm{Be}, \mathrm{BeO}$ and others are very strong mechanically.

Porous matrices are very quiet in operation. They provide jitter free cooling operation. This is because, the flow in porous media, if turbulent, it is homogeneous with extremely fine tübülènce structure-In Darcian and-nearDarcian regime it is laminar(more like micro channels).

Porous matrices provide very large extended surfaces internally (more like macro and micro channels, however, usually, an order magnitude higher) and they also provide "tortuosity" to the flow (unlike macro and micro channeling) which lends itself to increased dwell time for the coolant. Subsequently, porous matrices constitute, naturally, superior heat transfer media.In literature, it is quoted that with highly conductive metallic porous 
matrices one can remove as much as $7-8 \mathrm{~kW} / \mathrm{cm} 2$ heat flux [6,7, and 8 ]. Therefore the effective surface heat transfer coefficient of porous matices can be as large as those attainable with liquid metals and/or the micro channels. Our own experiments using copper mesh type porous matrices [9] as shown in Fig. 4 prove the high heat transfer enhancement available with a porous matrix in a generic APS tube to be used in our high heat load front end components .

\section{FEASIBILITY COMPUTATIONS}

From the large amount of literature available on boiling heat transfer in porous media, It is known that the porous matrix heat transfer exhibit a peculiarity that it goes to film boiling from nucleat boiling without going through the critical heat flux [10]. Therefore it is imperative that porous matrix should operate in single phase convective mode or at the most in sub-cooled nucleat boiling region.

Although we propose to use a foam back crystal we will consider here a more conventional silicon crystal about $10 \mathrm{~cm}$ wide $15 \mathrm{~cm}$ long with 500 holes of $1 \mathrm{~mm}$ in size for our cryogenic cooling feasibility computations. For the APS $X$-ray source we will consider the one with the largest total load of $10 \mathrm{~kW}$ level (APS Undulator A) which also produces the highest heat flux on the first crystal.

First, it may be instructive to calculate the theoretical limits of heat removal by single phase liquid $\mathrm{N}_{2}\left(\mathrm{LN}_{2}\right)$ at various flow rates of, say, 5,10 and $20 \mathrm{gpm}$ $(0.322,0.65$ and $1.29 \mathrm{l} / \mathrm{s}$ respsctively). Non-boiling is assured by pressurizing the system to the critical point of $\mathrm{N}_{2}$ which is $126.2 \mathrm{~K}$ and $3396 \times 10^{6} \mathrm{~Pa}$, or, in English units about $492 \mathrm{psi}$ ( $33.5 \mathrm{~atm}$ ). Then, the theoretical limit of sensible heat removal by $\mathrm{LN}_{2}$ introduced to the test section at a subcooled $66 \mathrm{~K}$ will be approximately as follows:

Flow (gpm)

5

10

20
$\mathrm{Q}(\mathrm{kW})$

17.8

35.6

71.1 
If $\mathrm{LN}_{2}$ is allowed to rise to $110 \mathrm{~K}$ at a system pressure of $492 \mathrm{psi}$ ( $33.5 \mathrm{~atm}$, then, there will be substantial sub-cooled boiling contribution to the total heat transfer in addition to the sensible heat removal from $66 \mathrm{~K}$ to $110 \mathrm{~K}$. Now let's return to our problem.

From elementary enthalpy considerations, Table 2 is constructed for the required mass flow rates of $\mathrm{N}_{2}$ at an inlet temperature of $66 \mathrm{~K}$.

For an arbitrary but feasible crystal geometry Table 3 lists the resulting flow and Reynolds number information. Table 4 lists the resulting heat transfer coefficients and the $\Delta T$ wall-fluid temperature differences.

If Case \#4 above is assumed to be a viable case, the resulting bulk fluid and wall temperatures along a flow channel can be computed to be:

\begin{tabular}{|c|c|c|}
\hline$Z$ (in.) & $T_{f}(K)$ & $\mathbf{T}_{\mathrm{W}}(\mathrm{K})$ \\
\hline 1 & 71.1 & 87.7 \\
\hline 2 & 75.9 & 92.6 \\
\hline 4 & 85.3 & 102 \\
\hline 6 & 95.3 & 112 \\
\hline 12 & 124.3 & 141 \\
\hline
\end{tabular}

$T_{\text {sat }}$ to correspond to $5 \mathrm{~atm}$ system pressure in Case \#4 is $94 \mathrm{~K}$. Therefore, the bulk fluid exceeds saturation temperatures within 6 in. length of the crystal and the saturated boiling region is reached which is undesirable.

A popular correlation among many, such as the Bowring correlation [11] on the estimate of the onset of boiling (ONB) point yields the following:

$$
\begin{aligned}
& \left(\Delta T_{\text {sat }}\right)_{O N B}=X \operatorname{Xr}_{f} \phi_{O N B}^{0.5} \\
& -\phi_{O N B}=h_{f}\left[\left(\Delta T_{\text {sat }}\right)_{O N}+\Delta T_{\text {SUB }}(2)\right]
\end{aligned}
$$

When the $\mathrm{LN}_{2}$ flowing through the channels reaches the saturation temperature of $94 \mathrm{~K}$ to correspond to the applied $5 \mathrm{~atm}$ system pressure (DTSUB) $=0$. Then, from data for $\mathrm{N}_{2}$

$$
X=0.00996\left[\dot{\mathrm{R}} / \mathrm{Btu} \mathrm{t}^{2}\right]^{0.5}
$$


$\operatorname{Prf}=2.016$

$$
\begin{aligned}
& \left(\Delta T_{\text {sat }}\right)_{\mathrm{ONB}}=0.00996 \times 2.016 \phi_{\mathrm{ONB}}^{0.5} \\
& \phi_{\mathrm{ONB}}=441\left(\Delta \mathrm{T}_{\text {sat }}\right)_{\mathrm{ONB}} \\
& \phi_{\mathrm{ONB}}=78.4 \mathrm{Btw} \mathrm{hr} \mathrm{f}^{2} \\
& \left(\Delta T_{\text {sat }}\right)_{\mathrm{ONB}}=0.179 \mathrm{R}=0.1 \mathrm{~K} \\
& \left(T_{w}\right)_{\text {ONB }}=169.3 \dot{\mathrm{R}}=94.1 \mathrm{~K}
\end{aligned}
$$

Again, using one of the many correlations available in literature on saturated boiling regime, such as the Roshenow correlation [11]

$$
\frac{C_{p f} \Delta T_{\text {sat }}}{i_{f g}}=C_{s}\left[\frac{\phi_{S C B}}{\mu_{f} i_{f g}} \sqrt{\frac{\sigma}{g\left(\rho_{f}-\rho_{g}\right)}}\right]^{0.33}\left[\frac{C_{p f}}{k_{f f}}\right]^{1.7}
$$

for Case \#4 one can calculate the following DT sat $_{\text {SSCB values (SCB- }}$ subcooled boiling)
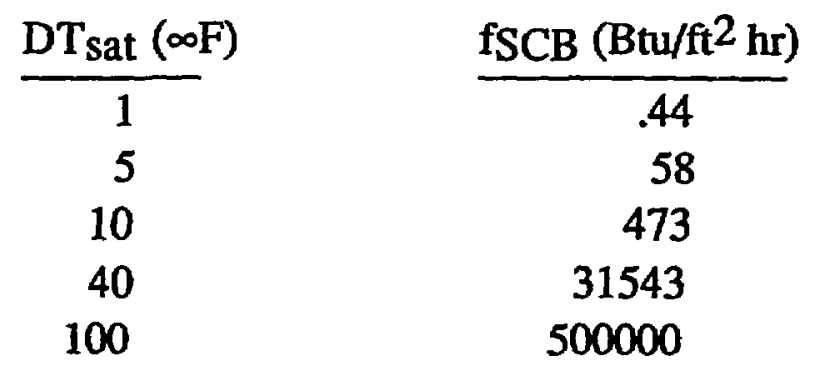
It is apparent that the Roshenow and Bowring correlations yield consistent results, namely, that onset of boiling (ONB) in the crystal channels occurs with negligible increase in the wall temperature above the saturation temperature once the bulk fluid is allowed to reach the saturation temperature at the prevailing system pressure. Then, the vapor generation will be explosive with undesirable results. To eliminate this possibility at the exit of the crystal channels conditions should allow the maintenance of some partial subcooling. This means that the system pressure at exit should be high enough to prevent the fluid bulk temperature from reaching saturation by some margin. It appears that this can be achieved, minimally, by maintaining a $103 \mathrm{psi}(7 \mathrm{~atm})$ system pressure ( $\mathbf{T}_{\text {sat }}$ $=98 \mathrm{~K}$ ) with a 6 -inch long crystal subject to $10 \mathrm{~kW}$ total load.

The above first cut feasibility study indicates that indeed it is possible to cool a high heat load optics using sub-cooled liquid nitrogen.

\section{FURTHER POROUS MATRIX CONSIDERATIONS}

Porous matrices have large internal surfaces. The internal surface area of a porous matrix with volumetric porosity of $\varepsilon$ is calculated as follows:

Spherical particles:

$$
S=6(1-\varepsilon) / D_{p}
$$

Wire like particles (wire meshes):

$$
S=4(1-\varepsilon) / D_{p}
$$

Simple calculations will indicate that internal surface area for heat transfer in porous matrices are enormous and will be dictated by the particle dimension.

The volumetric heat transfer coefficient in porous matrices is approximately given by:

$$
\mathrm{Nu} \cong \mathrm{C} \operatorname{Re} \operatorname{Pr} 1 / 3
$$


Using the Biot number limit of heat transfer one can optimize the pore size for a given material (such as $\mathrm{SiC}$ etc) and the coolant (LNE, gallium, water etc).

How well the heat can be transfered from the surface into the matrix of a porous matrix can be simply appreciated by applying finite or infinite fin assumption to a porous matrix element. At both cases the total heat transferred scales with $\cong(\mathrm{hPAk})^{1 / 2}$. It is seen here that the high conductivity attained by $\mathrm{Si}$, $\mathrm{SiC}, \mathrm{Be}, \mathrm{BeO}$ like materials at cryogenic temperatures is key to this efficient transfer of heat into the body of the matrix despite the poor thermal conductivity of the cryogenic coolants.

\section{REFERENCES}

[1] Shenoy, G.K. et el., "Status ofAdvanced Photon Source Project", The International Symposium on X-Ray Synchrotron Radiation and Advanced Science \& Technology, The Institute of Physical and Chemical Research (RIKEN). Japan Atomic Energy Research Institute (JAERI), 15-16 February, 1990

[2] Shenoy, G.K., Viccaro, P.J., and Mils, D.M., " Characteristics of the 7GeV Advanced Photon Source: A Guide for Users" APS Report, ANL-88-9, Feb. 1988

[22] Viccaro, P.J., " Power Distribution From Insertion Device Synchrotron X-Ray Sources", Workshop On High Heat Load X-Ray Optics, ANL/APS/TM6, Argonne, Illinois,Aug 3-5, 1989.

[3] Workshop on High Heat Load X-Ray Optics, (R.K. Smither and Andreas K. Freund co-chair), ANL/APS/TM-6, Argonne, Illinois, Aug 3-5,1989.

[4] Kuzay, T.M.,"Process of Making Cryogenically Cooled High Thermal Performance Crystal Optics", U.S.D.O.E Patent Applied for, \#S69384.

[5] Bilderback, D.H., "The Potential of Cryogenic Silicon and Germanium X-Ray Monochromators for Use With large Synchrotron Heat Loads", Nucl. Inst. and Meth. A246 (1986), pp.434-436

[6] Freund, Andreas.," Optics for the European Synchrotron Radiation facilities", Workshop On High Heat Load X-Ray Optics, ANL/APS/TM-6, Argonne, Illinois,Aug 3-5, 1989 
[7] Schildkamp W., Bilderback Donoald and Shen Q., " The Feasibility of Liquid Propane Cooling of X-Ray Monochromator Crystals", loc. cit.

[6] Apollonov,V.V., etal.," Stability Parameters of Mirror Surfaces Used in Laser Reflectiors" Sov. Tech. Phys. Let. 1(6), Jun.1975, pp.240-1.

[7] Apollonov,V.V., etal.," Enhanced Damage for Mirrr-Finish Metal Surfaces Cooled by Open Pore Structures", Sov. Tech. Phys. Let. 4(10), Oct. 1978,pp.480-1

[8] Apollonov,V.V., etal.," Thermophysical Principles of Cooled Laser Optics Based on New Type Penetrable Structures", Exp. Heat Transfer. Fluid Mech., and Thermodynamics (Eds. R.K. Shah, E.N. Ganic and K.T. Yang), elsevier Science Publishing Co.,Inc., 1988.

[9]Kuzay,T.M. et al., "Enhanced Heat Transfer With Metal-Wool Filled Tubes", Proc. ASME/JSME Thermal Engineering Joint Conf. (Edtrs. J.R.Lloyd and Y. Kurosaki), Book No.10309E- 1991

[10] S. Fukusako, s., et al, "Boiling Heat Transfer In a Liquid- Saturated Porous Bed", loc.cit.

[11] Collier, John G., Convective Boiling and Condensation, McGraw-Hill Book Company, 1972. 


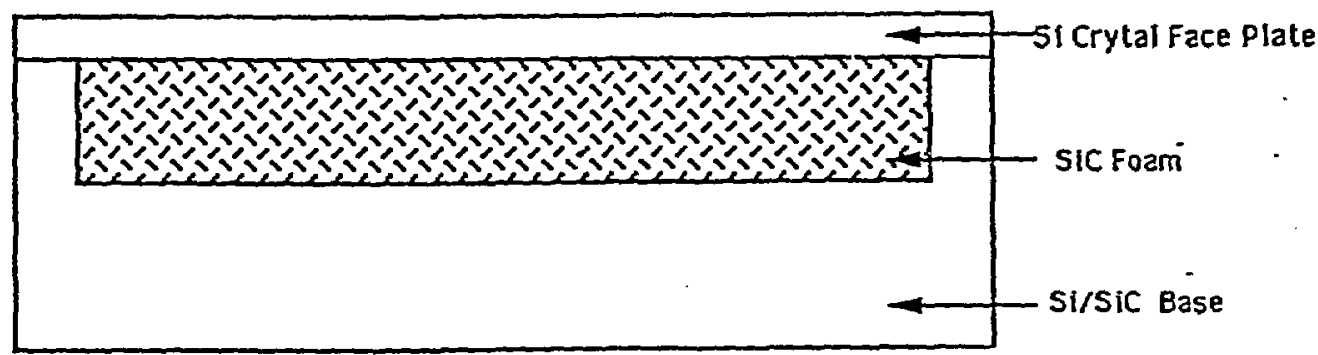
. 


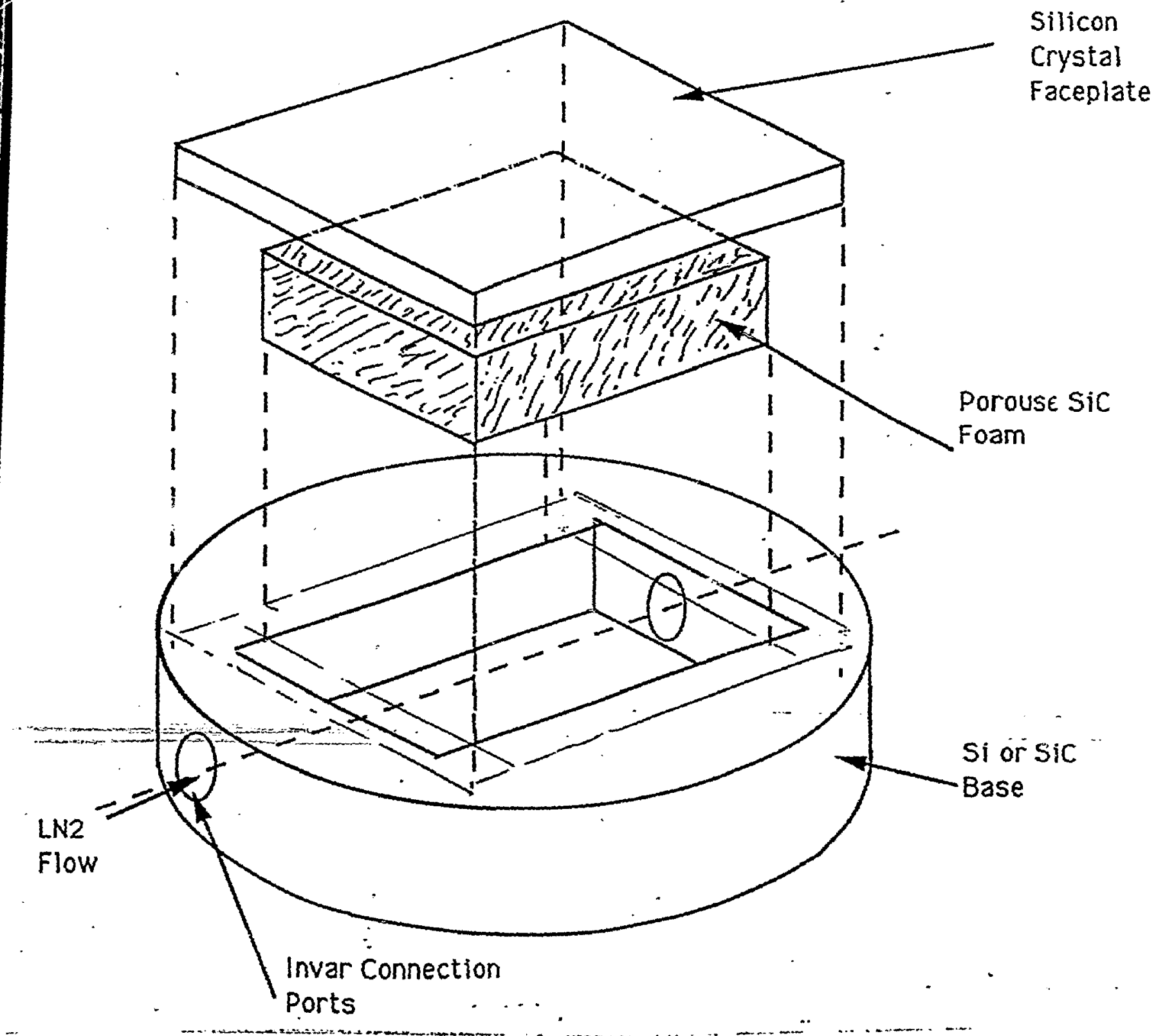

Fig. 2. Schematic of a conceptual Si crystal assembly using a porous heat exchanger. 


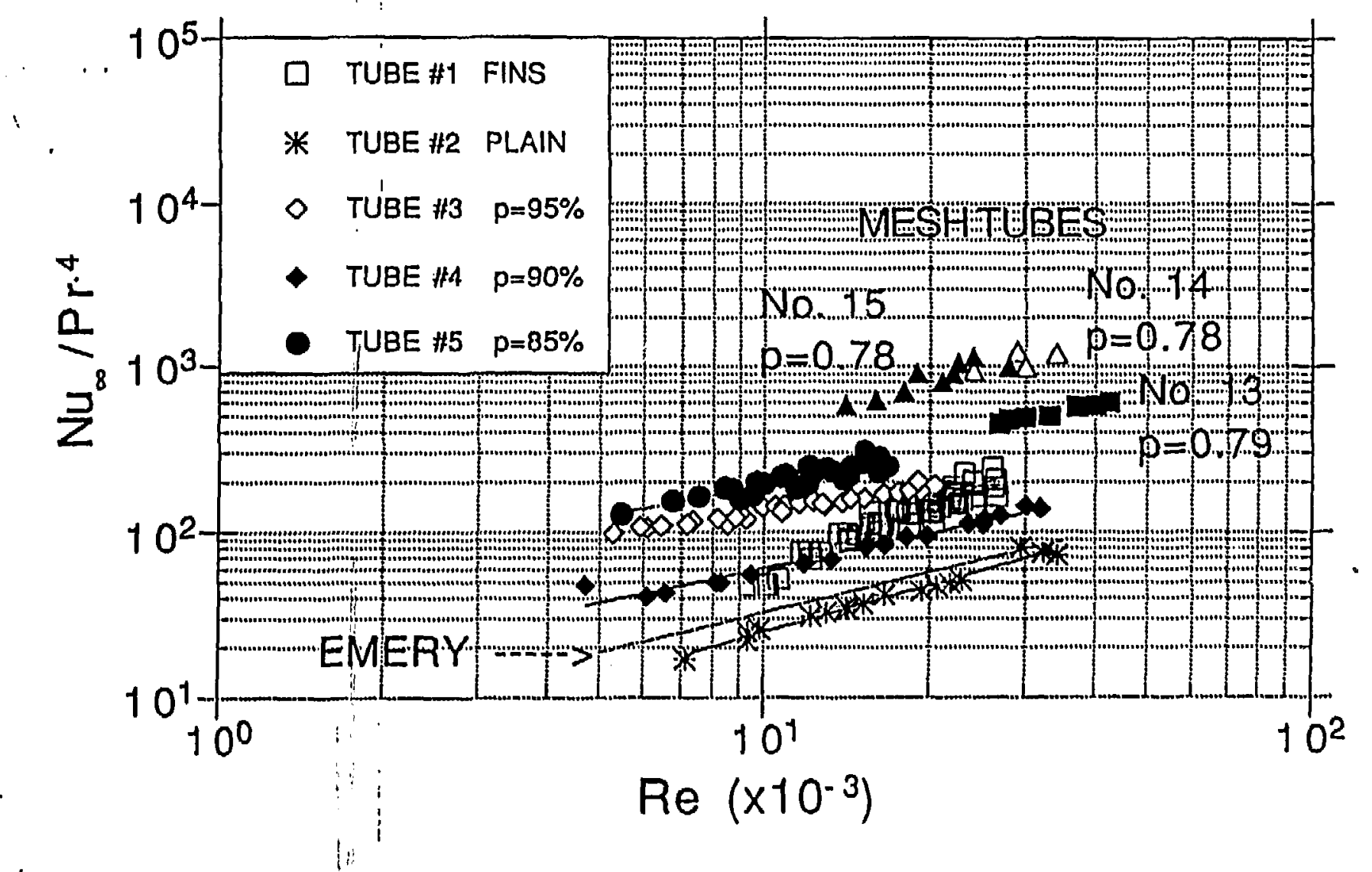

Fig. 3. Heat transfer data with porous copper mesh in tubes 
Table 1.: Design Parameters of Various APS Insertion Devices for a Ring Energy of $7 \mathrm{GeV}$ and $100 \mathrm{~mA}$ Stored Current

\begin{tabular}{|c|c|c|c|c|c|c|c|}
\hline \multirow[t]{2}{*}{ (2) } & \multicolumn{4}{|c|}{ Undulators } & \multicolumn{2}{|c|}{ Wigglers } & \multirow{2}{*}{$\begin{array}{l}\text { Bending } \\
\text { Magnet }\end{array}$} \\
\hline & $A$ & $\overline{\mathbf{B}}$ & $\mathrm{C}$ & $\overline{\mathbf{D}}$ & $\bar{A}$ & $\overline{\mathbf{B}}$ & \\
\hline \multirow{5}{*}{$\begin{array}{l}\text { Period length }[\mathrm{cm}] \\
\text { Device length }[\mathrm{m}] \\
\text { Number of periods } \\
\text { Max. magnetic field } B_{0}[T] \\
\text { Characteristic energy } E_{c}[\mathrm{kcV}]\end{array}$} & 3.1 & 2.1 & 20.0 & 8.0 & $15.0^{\prime}$ & 25.0 & $\mathrm{NA}$ \\
\hline & 5.00 & 5.00 & 5.00 & 5.00 & 1.50 & 5.00 & 3.06 \\
\hline & 160 & 238 & 25 & 62 & 10 & 20 & $\mathrm{NA}$ \\
\hline & 0.80 & 0.40 & 0.15 & $1: 00$ & 1.00 & 0.30 & 0.6 \\
\hline & 26.0 & 13.0 & 4.9 & 32.6 & 32.6 & 9.8 & 19.5 \\
\hline \multirow{3}{*}{$\begin{array}{l}1 / \gamma \text { [mrad] } \\
\text { Max. deflection parameter, } \mathrm{K} \\
\mathrm{K} / \gamma \text { [mrad] }\end{array}$} & 0.073 & 0.073 & 0.073 & 0.073 & 0.073 & 0.073 & 0.073 \\
\hline & 2.51 & 1.03 & 2.81 & 8.76 & 13.96 & 7.00 & NA \\
\hline & 0.183 & 0.075 & 0.205 & 0.639 & 1.019 & 0.511 & NA \\
\hline \multirow{3}{*}{$\begin{array}{l}\text { Total power }[\mathrm{kW}] \\
\text { Peak power }\left[\mathrm{kW} / \mathrm{mrad}^{2}\right] \\
\text { Peak power @ } 15 \mathrm{~m}\left[\mathrm{~kW} / \mathrm{mm}^{2}\right]\end{array}$} & 10.0 & 2.5 & 0.35 & 15.5 & 4.6 & 1.4 & $0.52 *$ \\
\hline & 333 & 250 & 9.8 & 160 & $26.0_{i}^{i}$ & 15.6 & 1.78 \\
\hline & 1.5 & 1.1 & 0.04 & 0.71 & 0.12 & 0.07 & 0.008 \\
\hline "“" @24 m [kW/mm²] & 0.58 & 0.43 & 0.02 & 0.28 & 0.05 & 0.03 & 0.003 \\
\hline$" @ 30 \mathrm{~m}\left[\mathrm{~kW} / \mathrm{mm}^{2}\right]$ & 0.37 & 0.28 & 0.01 & 0.18 & 0.03 & 0.02 & 0.002 \\
\hline$@ 40 \mathrm{~m}\left[\mathrm{~kW} / \mathrm{mm}^{2}\right]$ & 0.21 & 0.16 & 0.01 & 0.10 & 0.02 & 0.01 & 0.001 \\
\hline
\end{tabular}


Table 2. Condensed Thermophyslenl Properlles of $\mathrm{N}_{2}$ in the Cryogenle Range of Interest

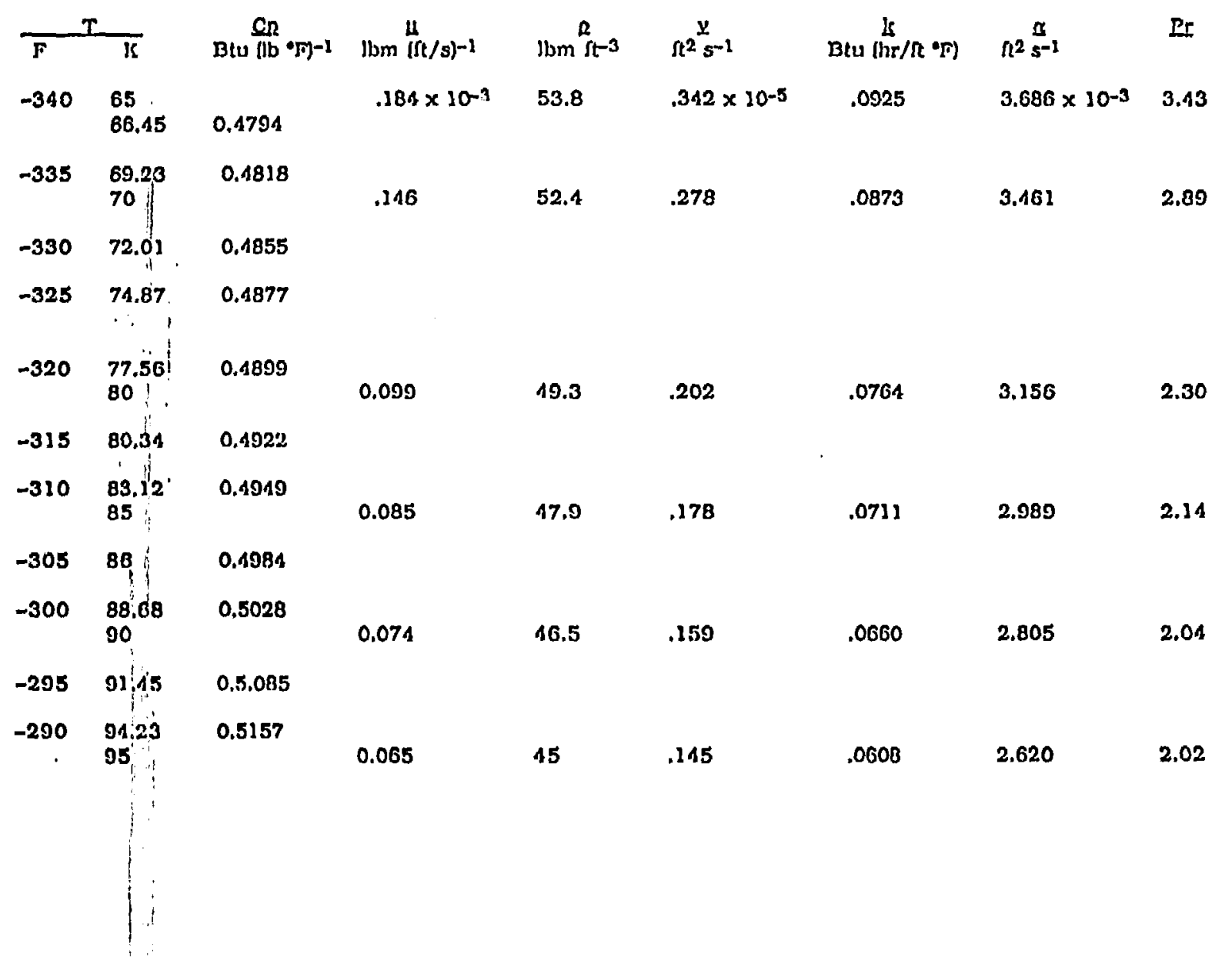


Table 3. Mass Fou Rate

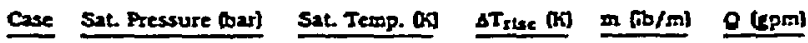

$\begin{array}{llllll}1 & 1 & 77 & 11 & 3549 & 0.45 \\ 2 & 2 & 84.5 & 28.5 & 2101 & 5.15 \\ 3 & 3 & 88 & 22 & 1759 & 4.33 \\ 4 & 5 & 94 & 28 & 1375 & 3.54 \\ 5 & 7 & 99 & 33 & 1161 & 3.01 \\ 6 & 10 & 105 & 40 & 951 & 2.48\end{array}$

Table 4. 500 Hole Crystal (I mon $\phi$ Holes) How-Reynolds Number Datz*

\begin{tabular}{|c|c|c|c|}
\hline Case & $\left.G \mathrm{ab} / \mathrm{hs} \mathrm{ft}^{2}\right)$ & (ft/s) & Re \\
\hline 1 & $8.4 \times 10^{5}$ & 4.45 & 5247 \\
\hline 2 & 4.97 & 2712 & 3814 \\
\hline 3 & 4.20 & 2.31 & 3757 \\
\hline 4 & 3.25 & 1.66 & 3030 \\
\hline 5 & 2.80 & 1.59 & 2936 \\
\hline 6 & 2.25 & 1.31 & 2597 \\
\hline
\end{tabular}

Jotal Dow surface area -2.54 $\mathrm{It}^{2}$

Jotal Dow area $-0.6007 \mathrm{in}^{2}$

-

Table 5. 500 Hole Geomety. Heat Transfer Coeffidents and the WallBulk Fluld Temperature Differences

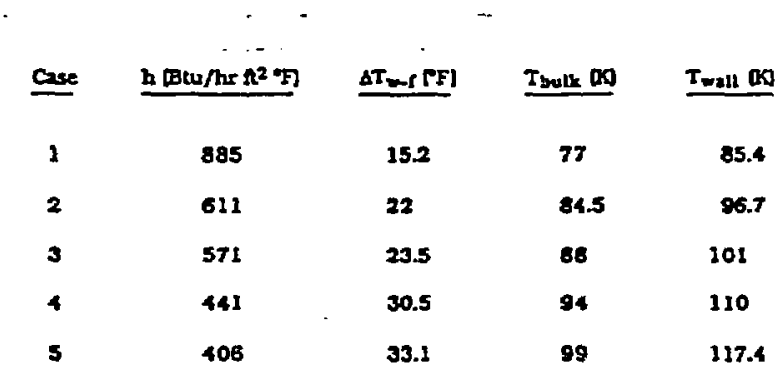

